BTA 1

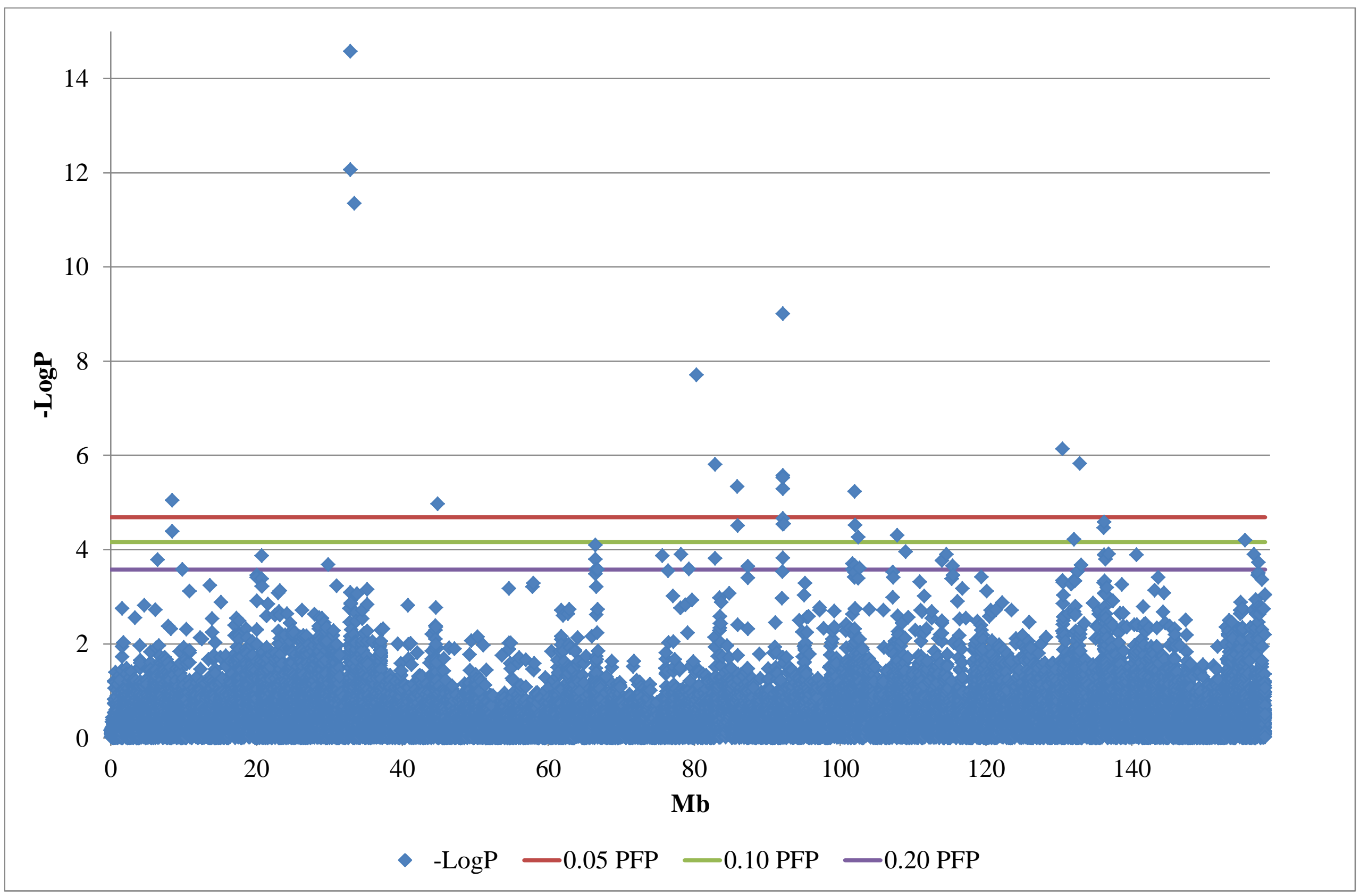

BRD pools $-\log \mathrm{P}$ chr e.xlsx 
BTA 2

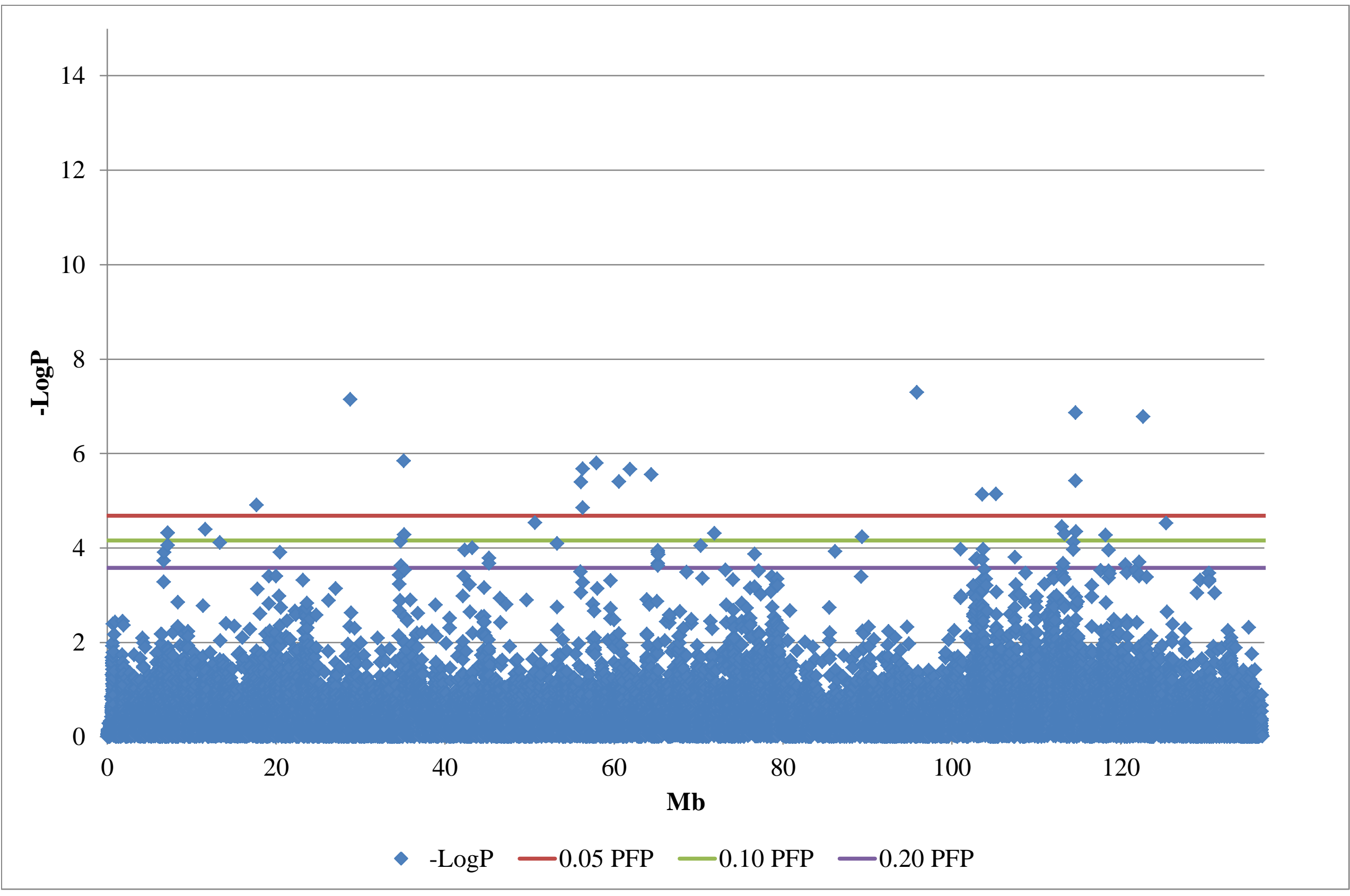

BRD pools $-\log P$ chr e.xlsx 


\section{BTA 3}

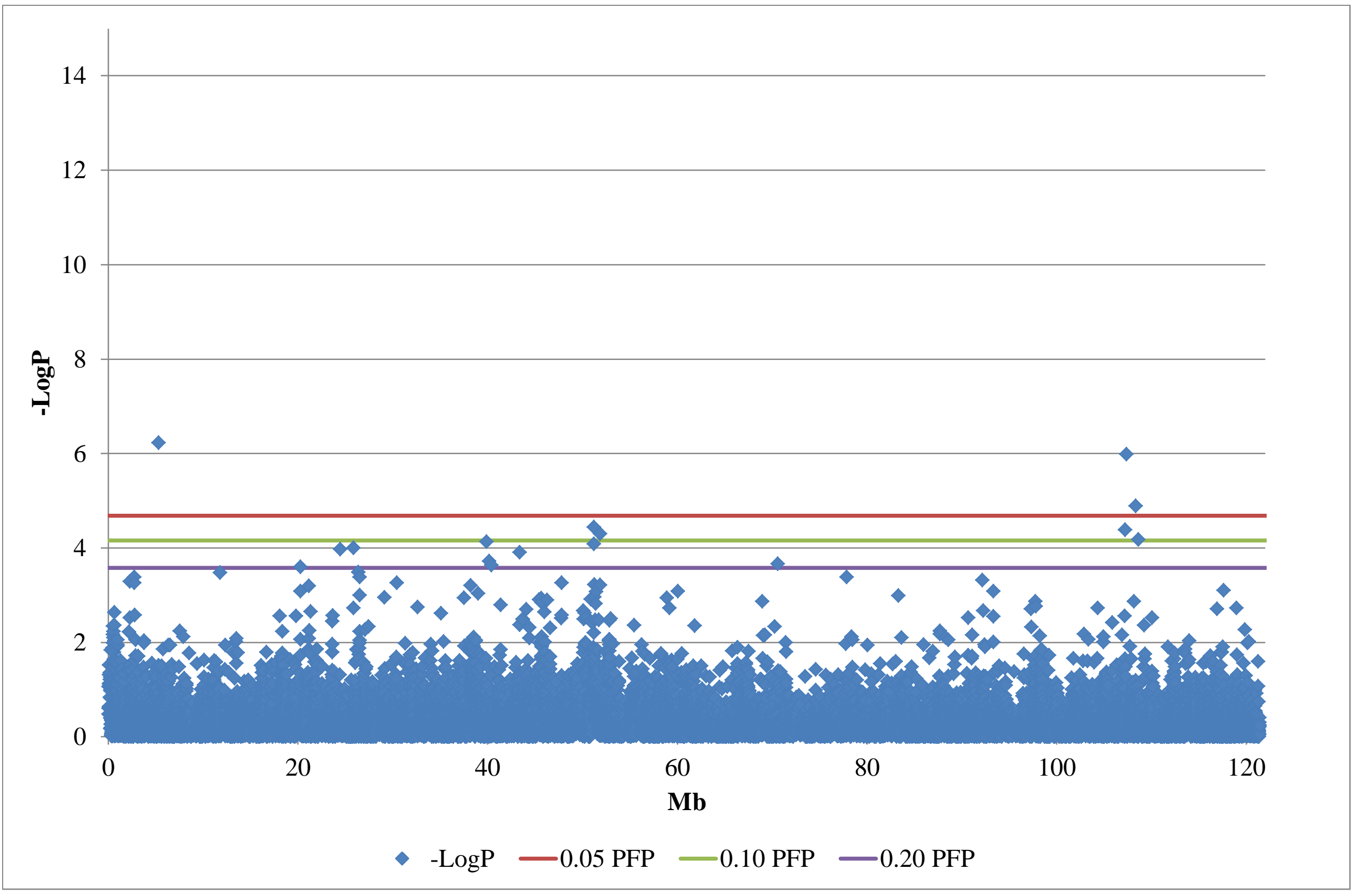

BRD pools - $\log \mathrm{P}$ chr e.xlsx 
BTA 4

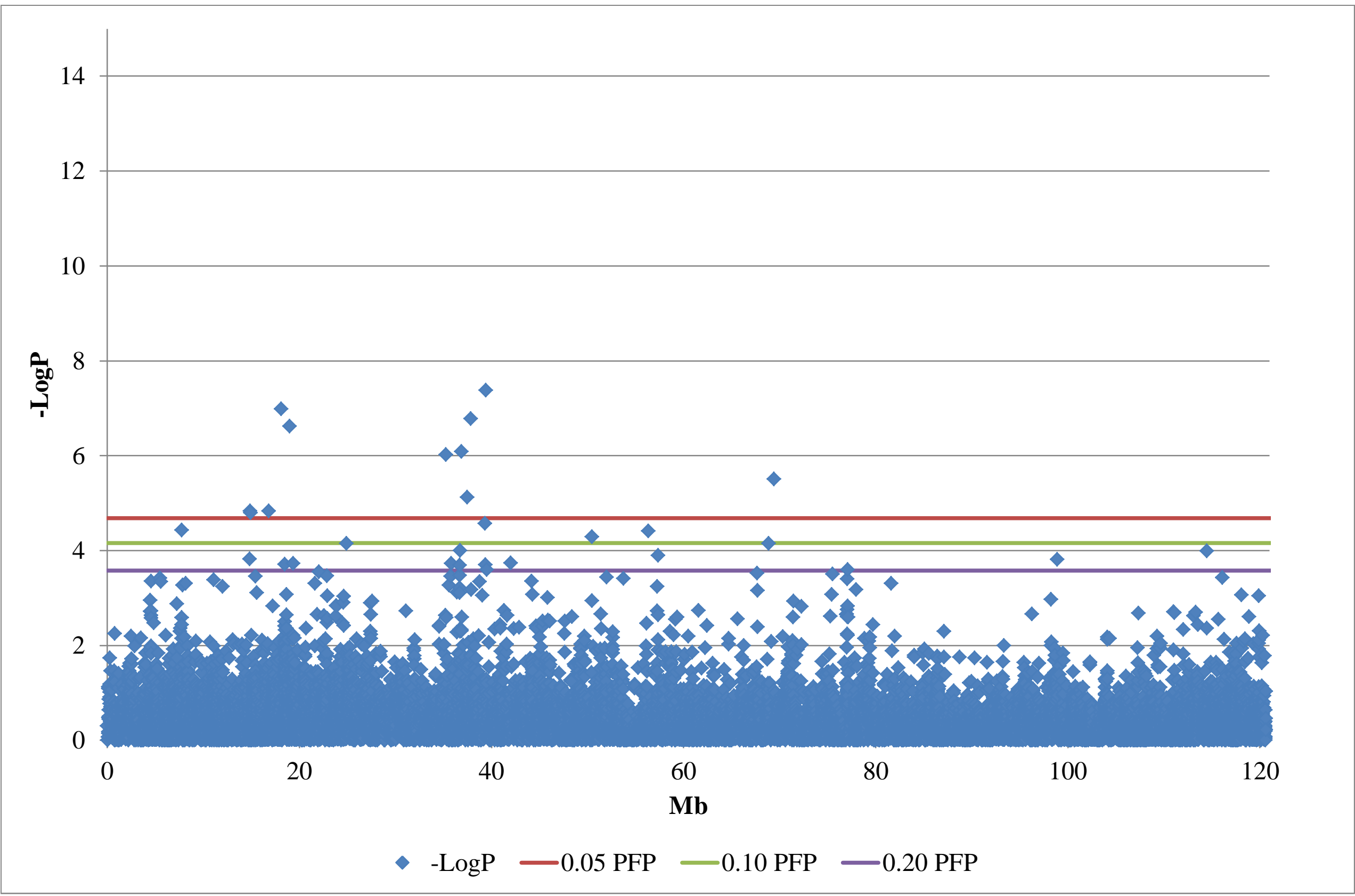

BRD pools - $\log \mathrm{P}$ chr e.xlsx 


\section{BTA 5}

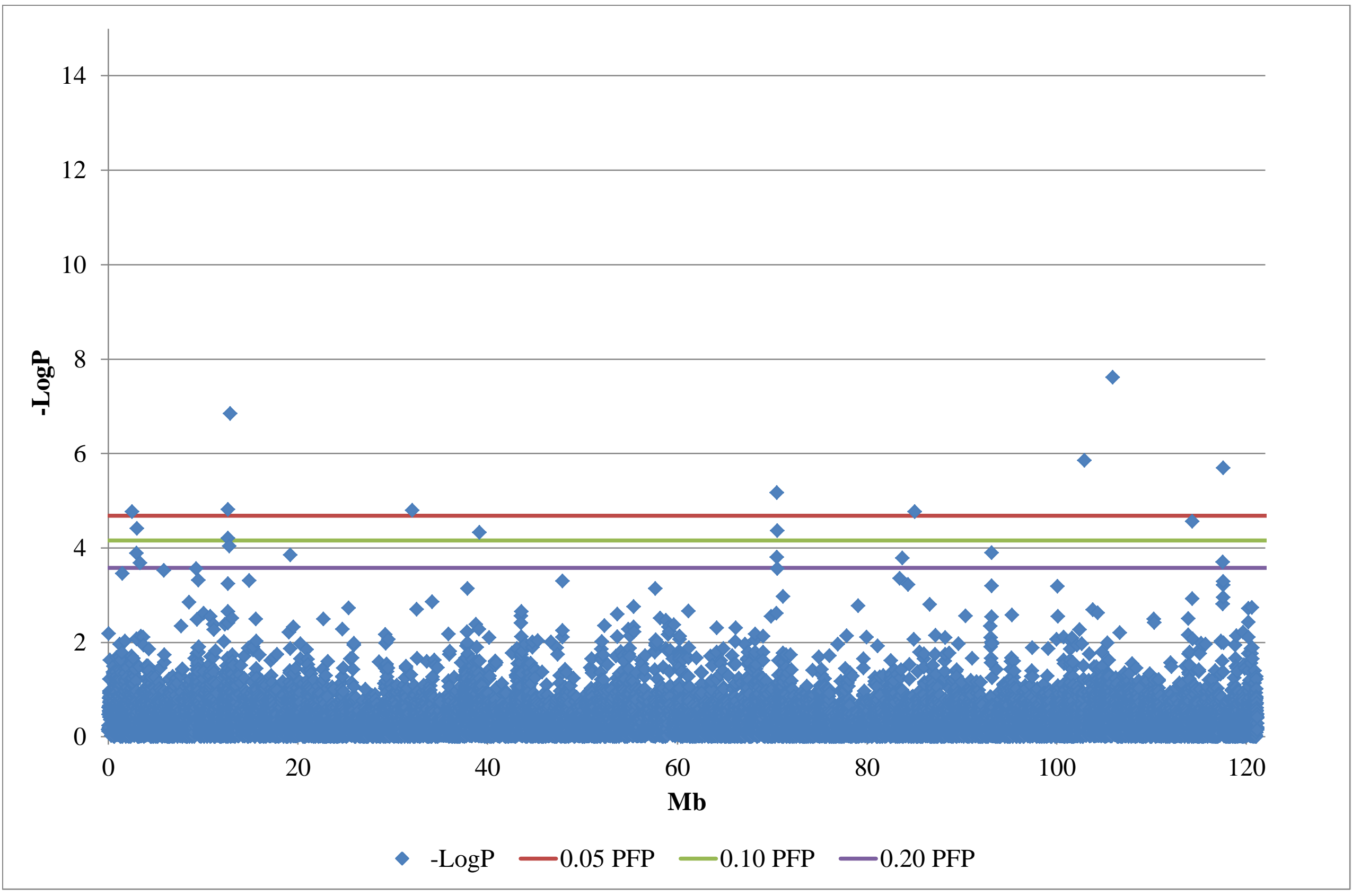

BRD pools - $\log \mathrm{P}$ chr e.xlsx 


\section{BTA 6}

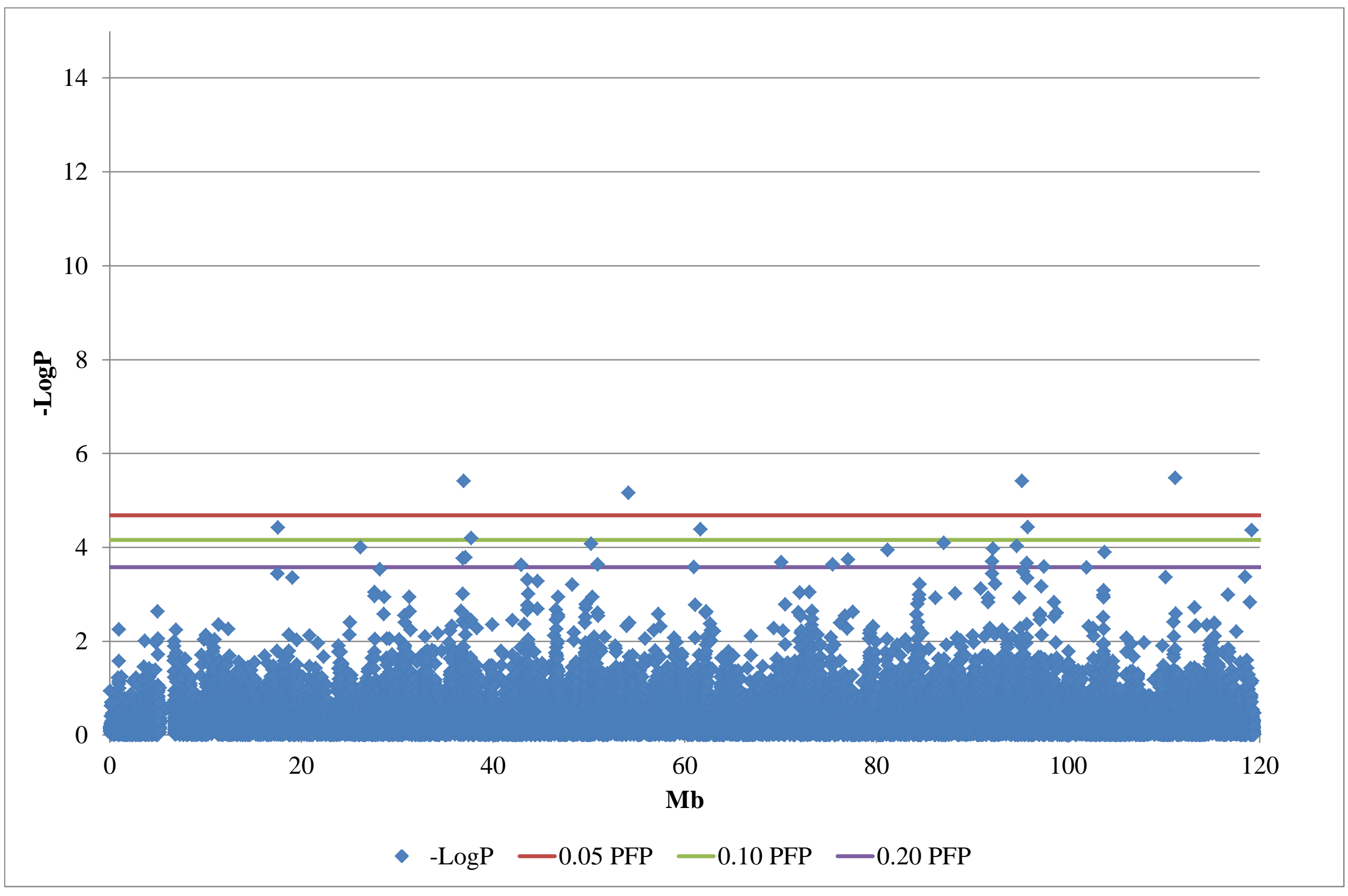

BRD pools $-\log \mathrm{P}$ chr e.xlsx 


\section{BTA 7}

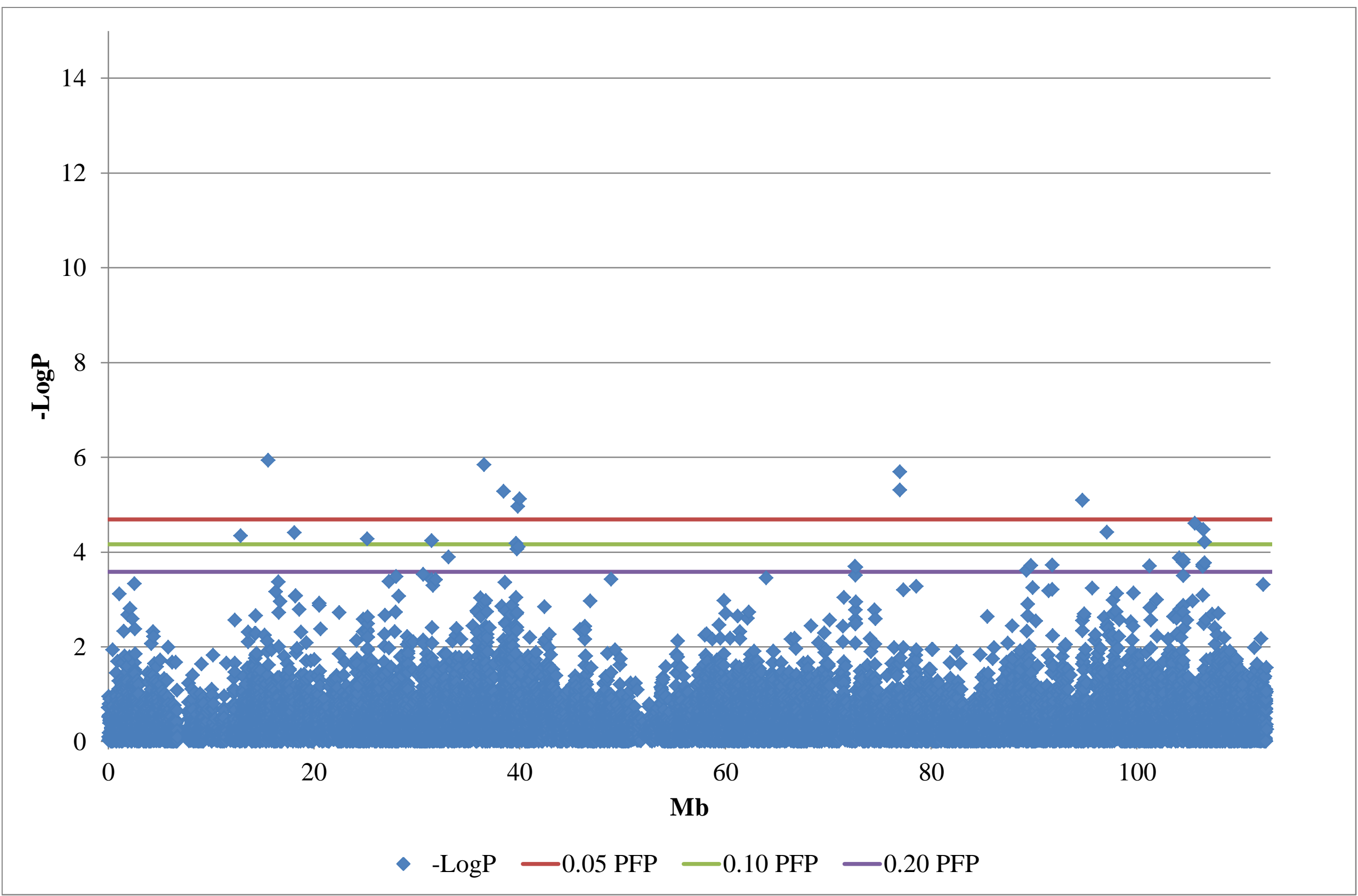

BRD pools $-\log \mathrm{P}$ chr e.xlsx 


\section{BTA 8}

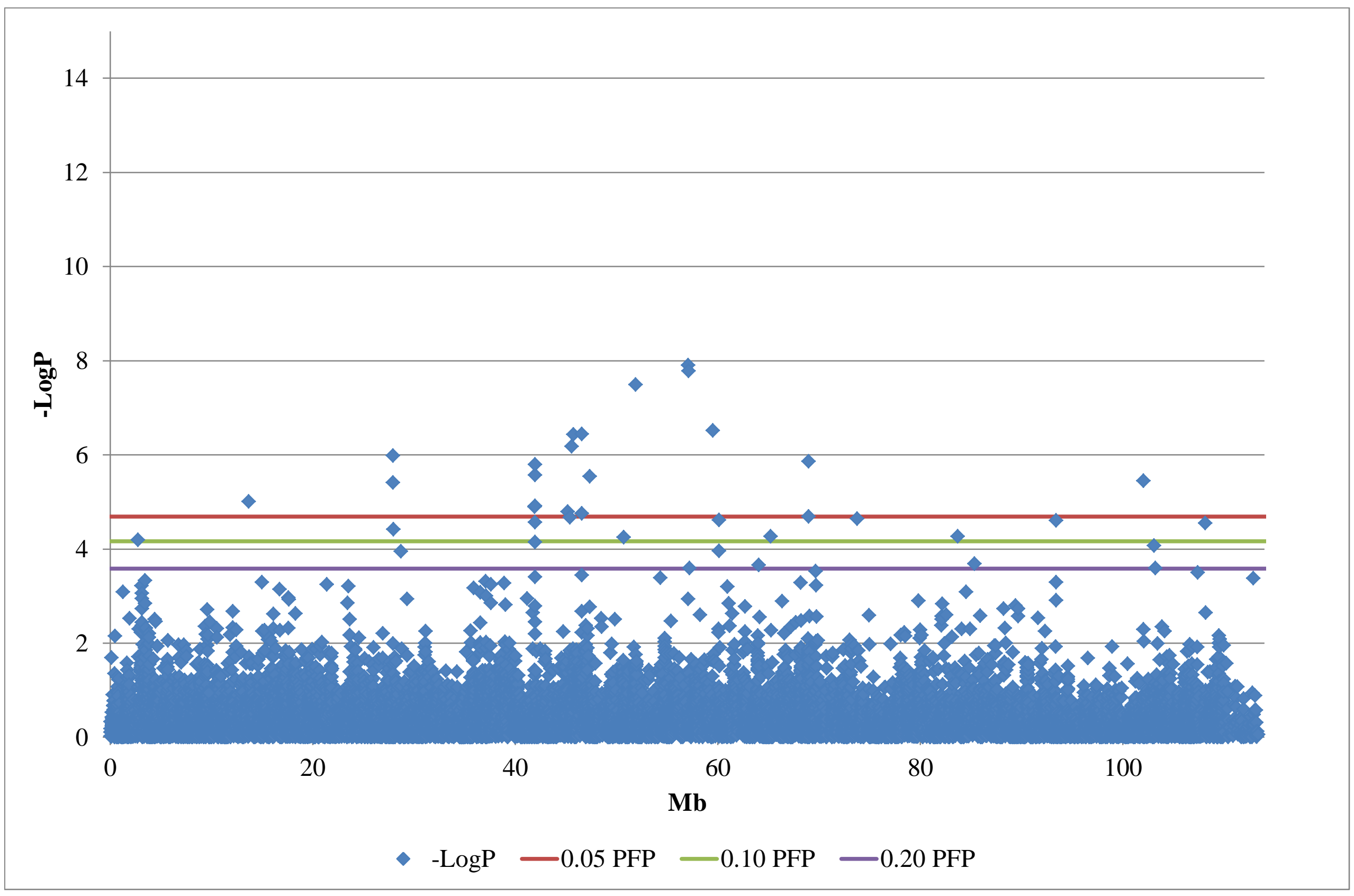

BRD pools - $\log \mathrm{P}$ chr e.xlsx 


\section{BTA 9}

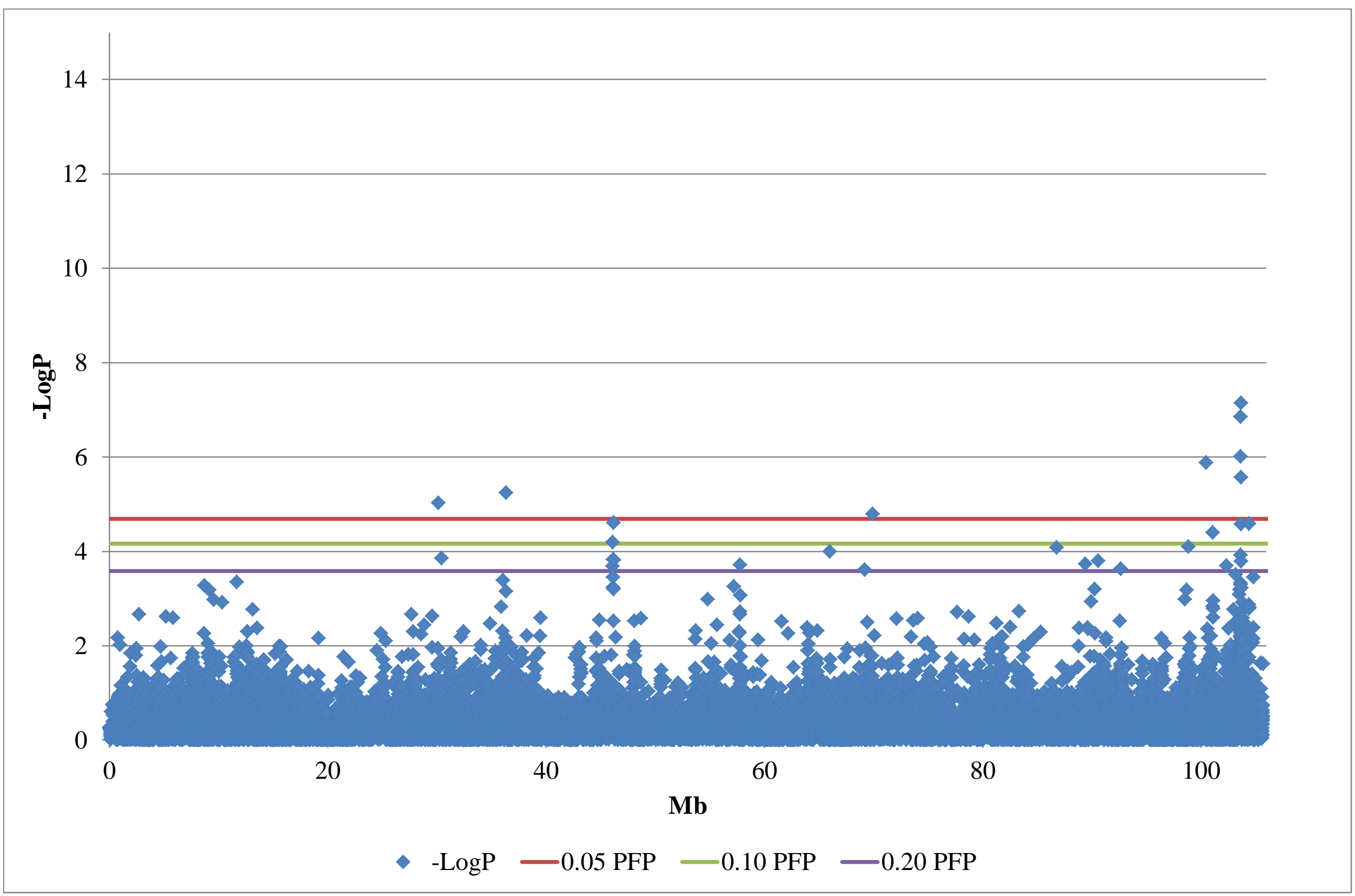

BRD pools - $\log \mathrm{P}$ chr e.xlsx 
BTA 10

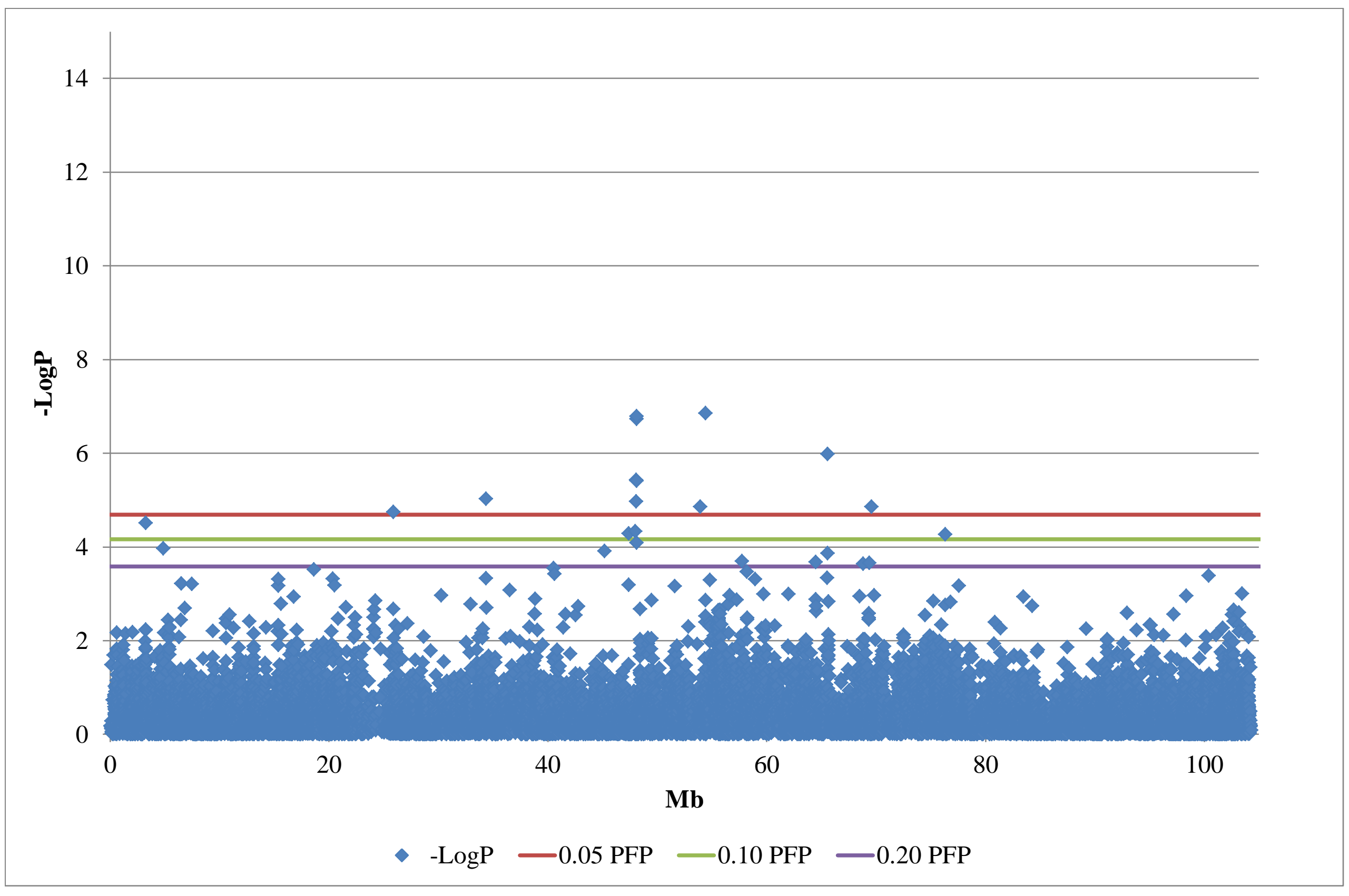

BRD pools $-\log \mathrm{P}$ chr e.xlsx 
BTA 11

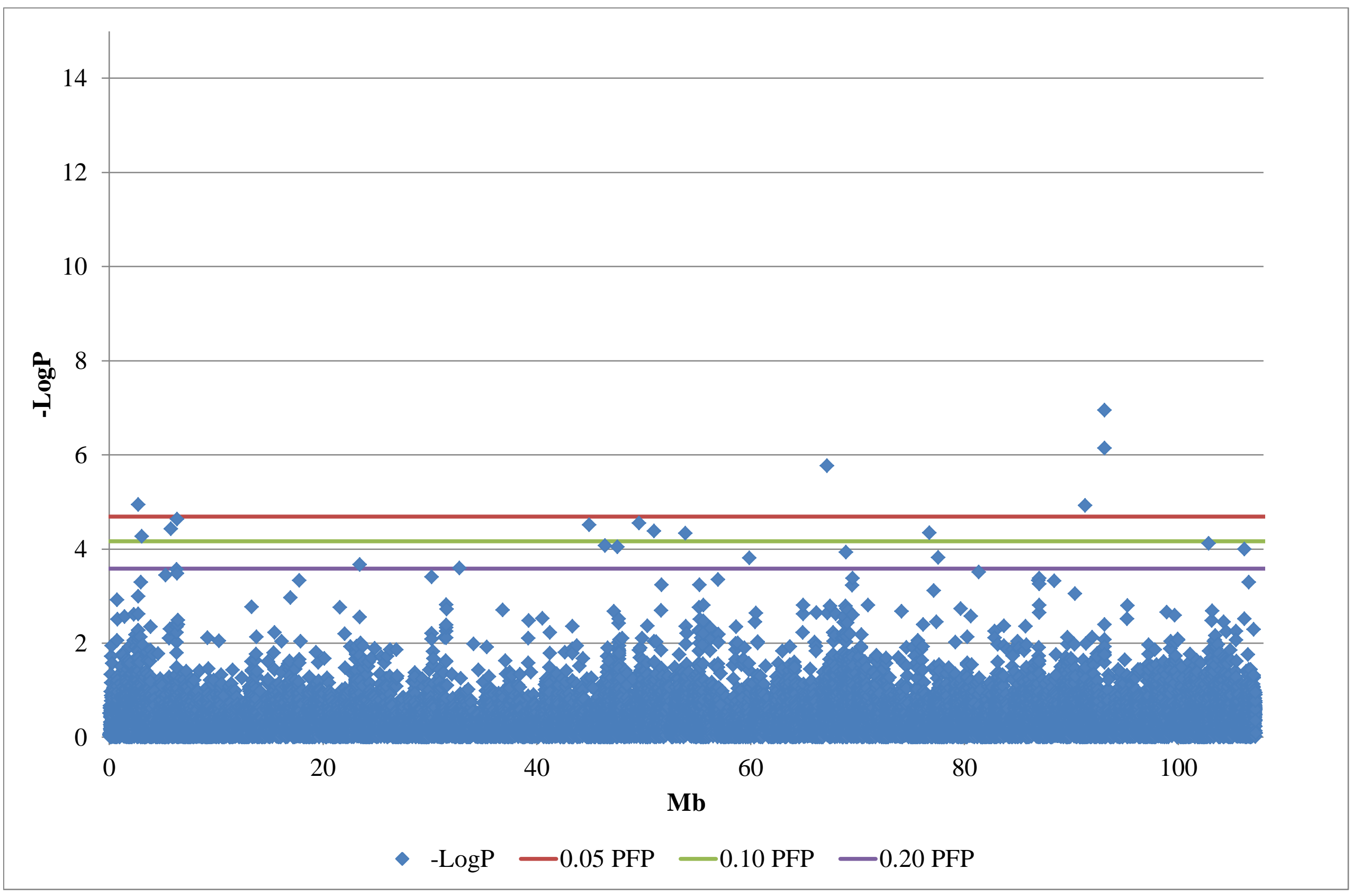

BRD pools - $\log \mathrm{P}$ chr e.xlsx 
BTA 12

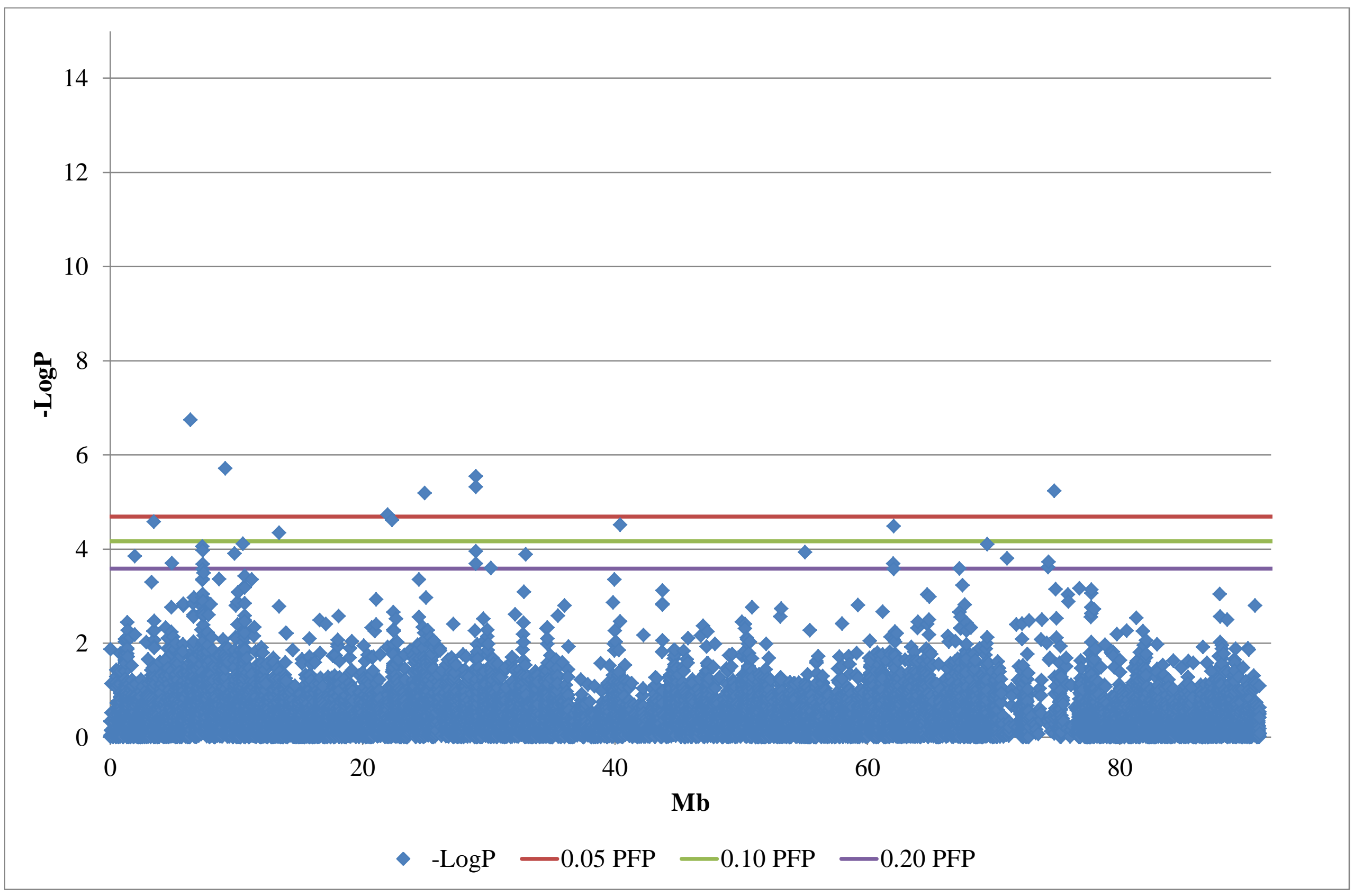

BRD pools $-\log \mathrm{P}$ chr e.xlsx 
BTA 13

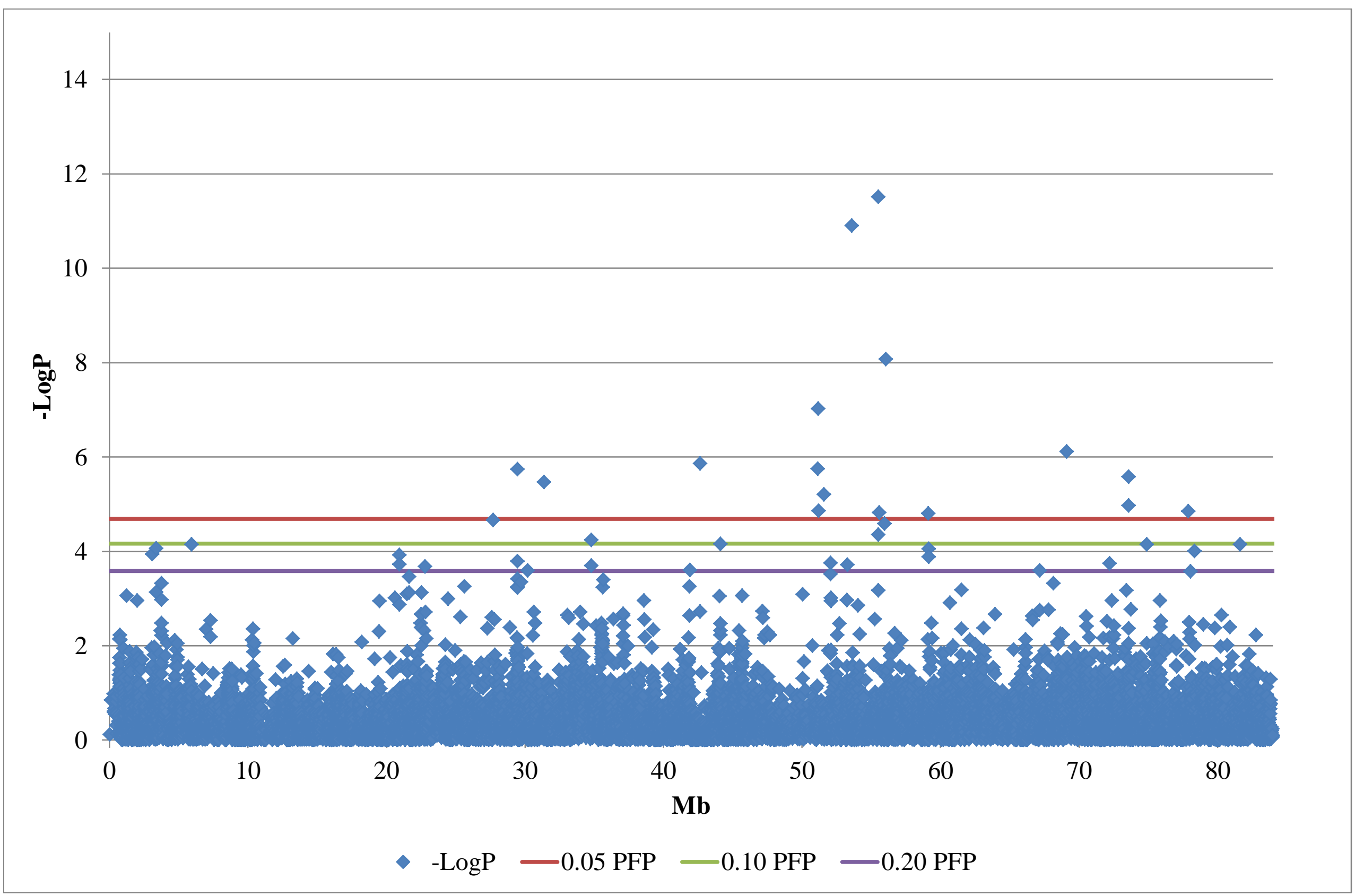

BRD pools $-\log P$ chr e.xlsx 
BTA 14

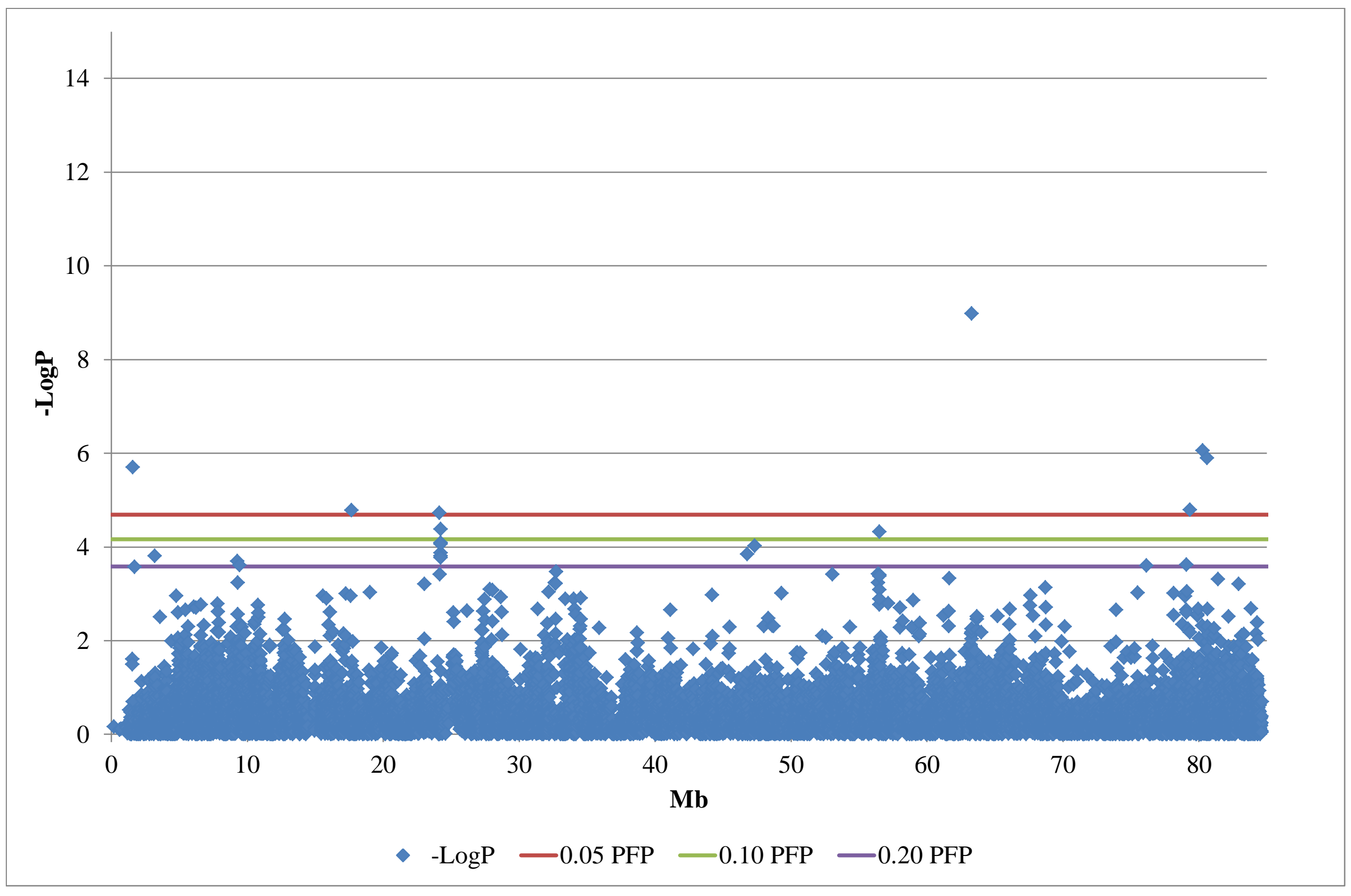

BRD pools $-\log \mathrm{P}$ chr e.xlsx 
BTA 15

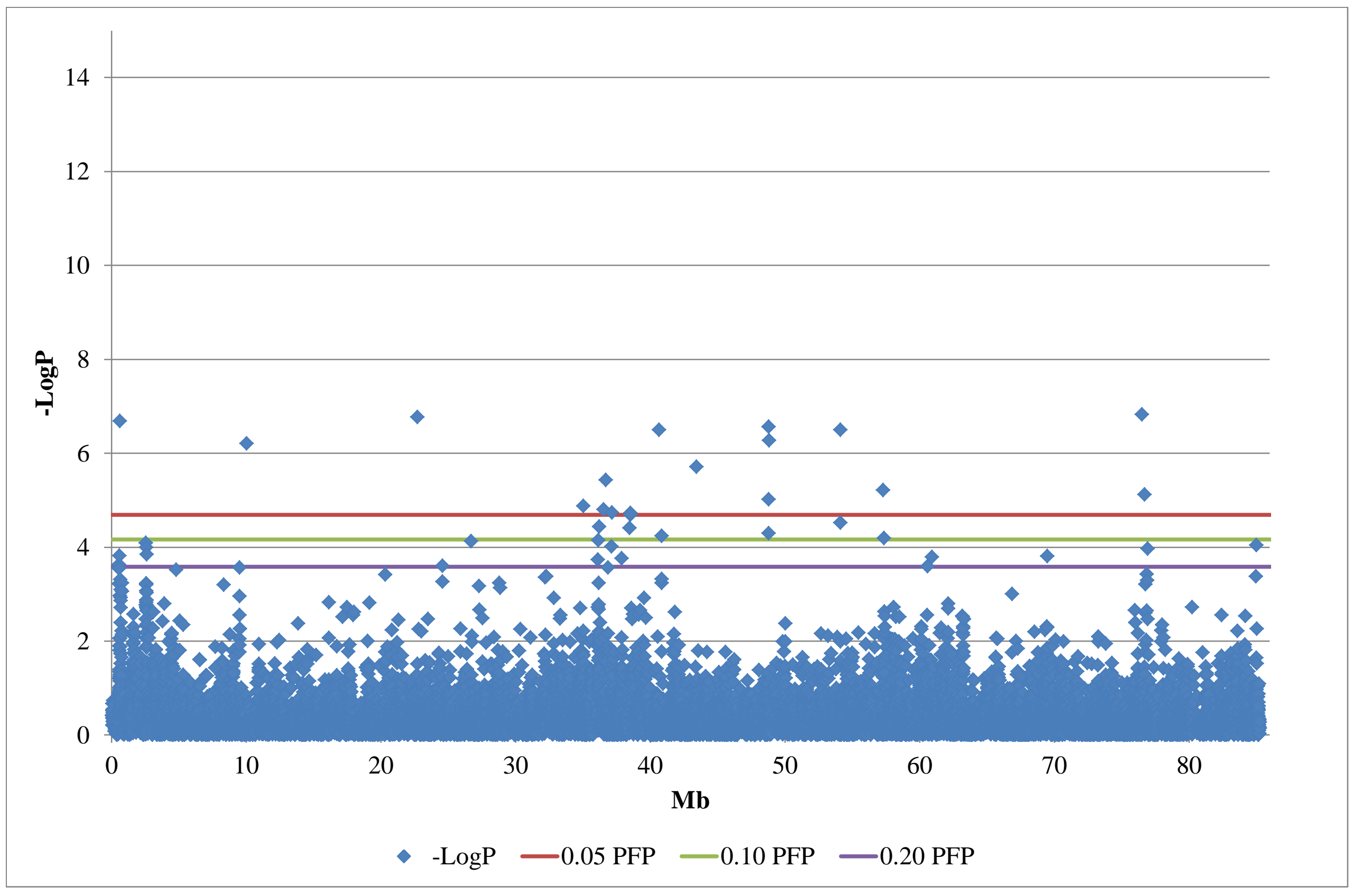

BRD pools $-\log \mathrm{P}$ chr e.xlsx 
BTA 16

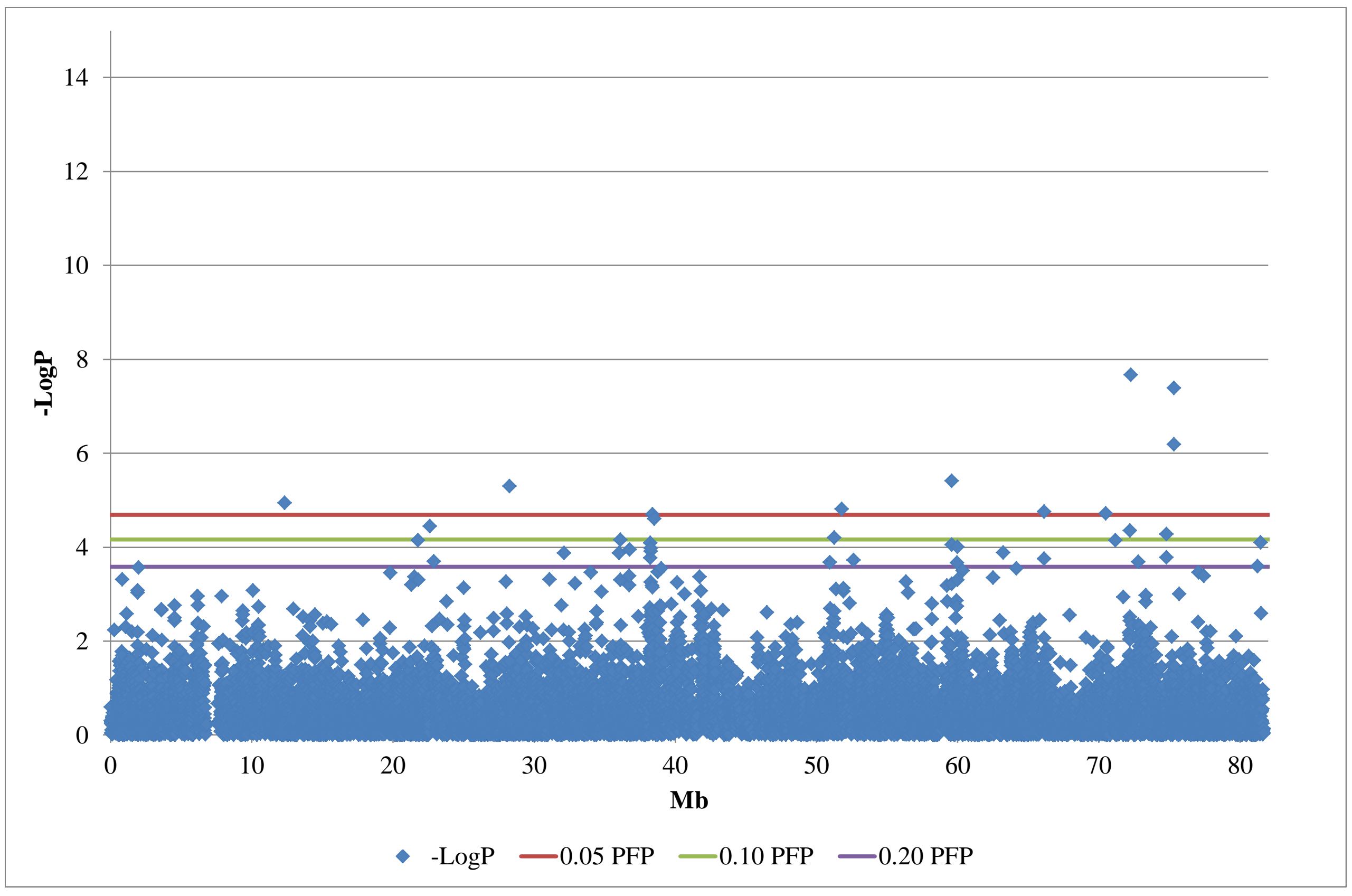

BRD pools $-\log \mathrm{P}$ chr e.xlsx 
BTA 17

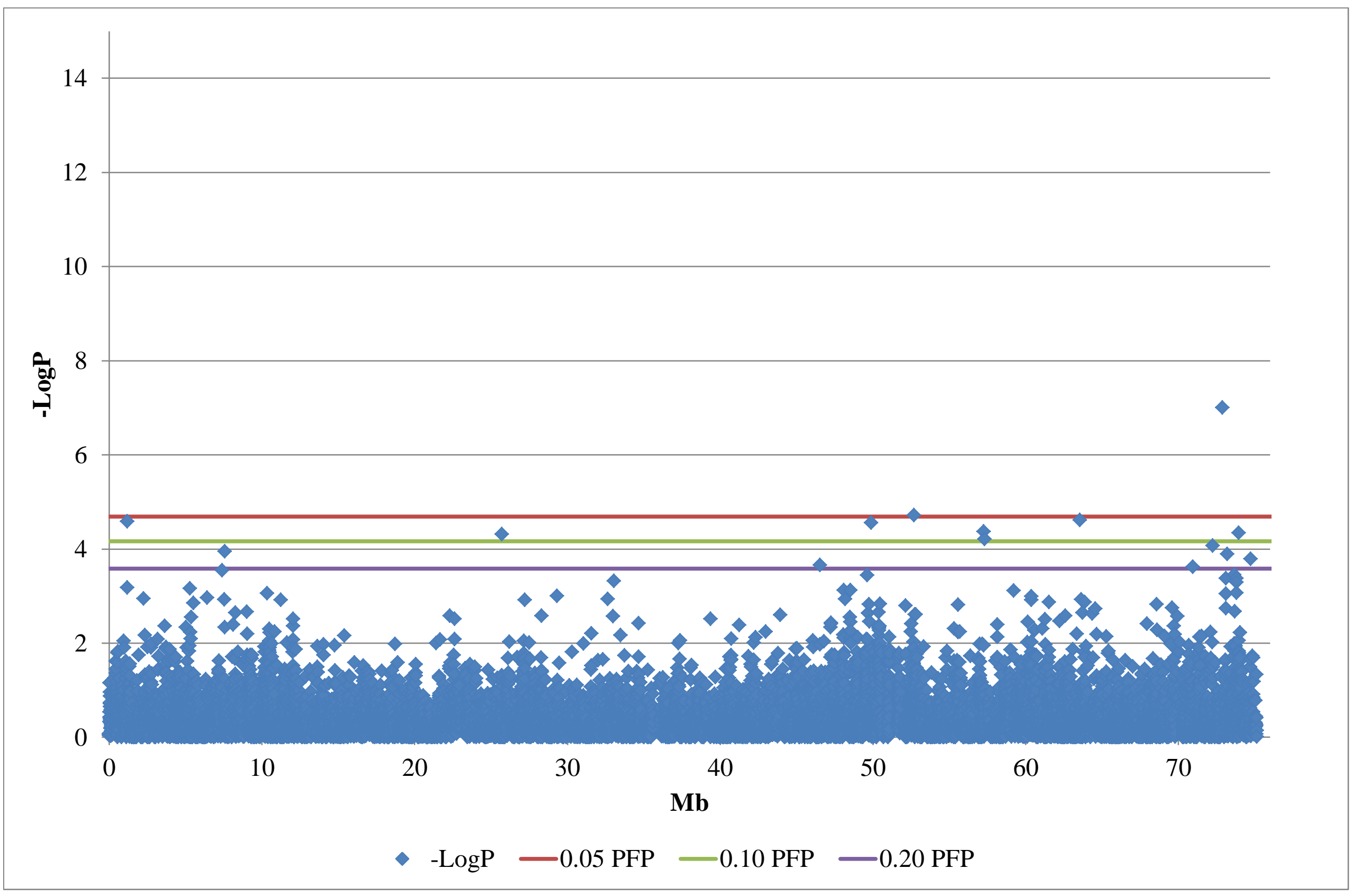

BRD pools - $\log \mathrm{P}$ chr e.xlsx 
BTA 18

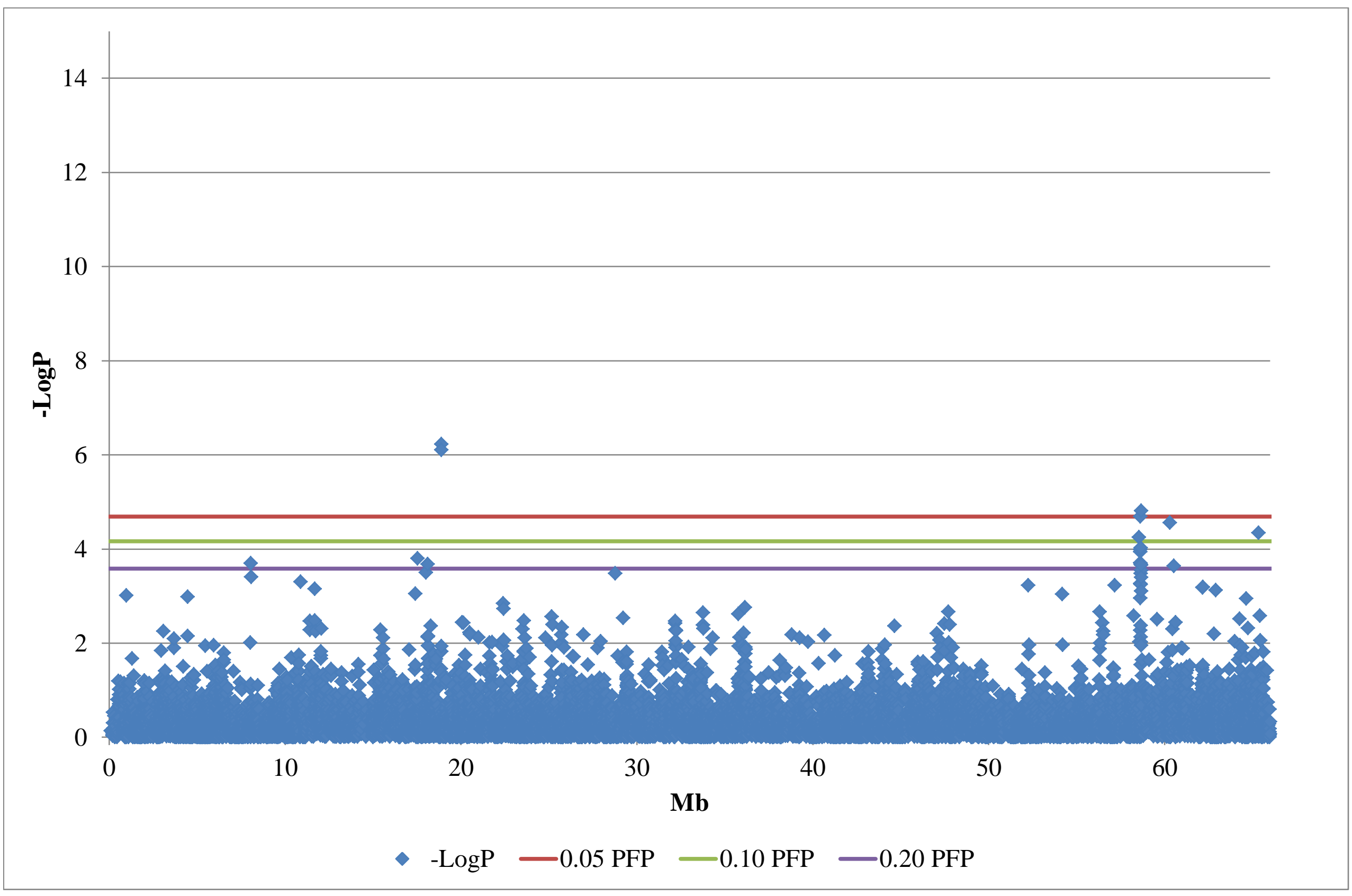

BRD pools $-\log \mathrm{P}$ chr e.xlsx 
BTA 19

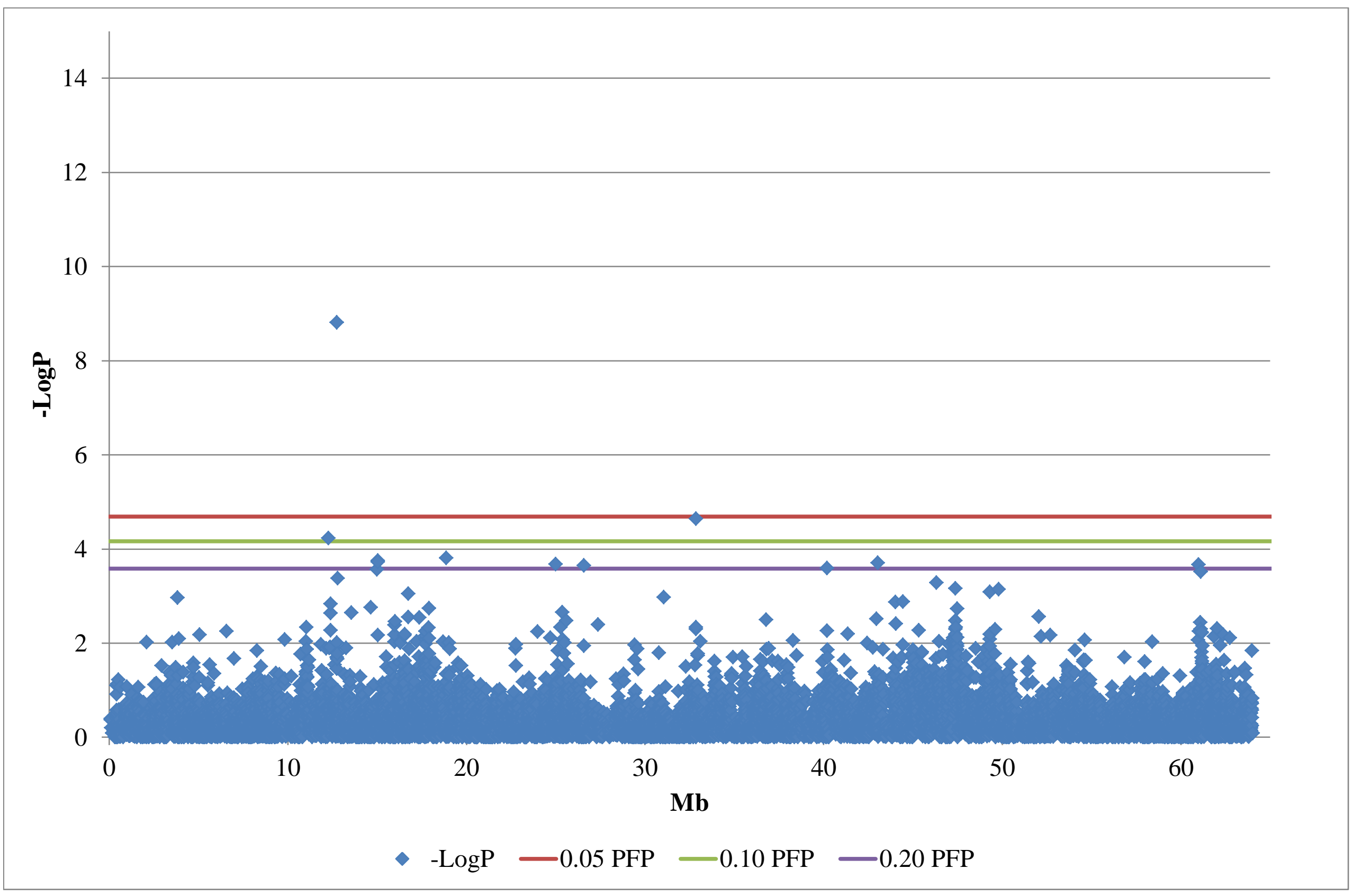

BRD pools - $\log \mathrm{P}$ chr e.xlsx 
BTA 20

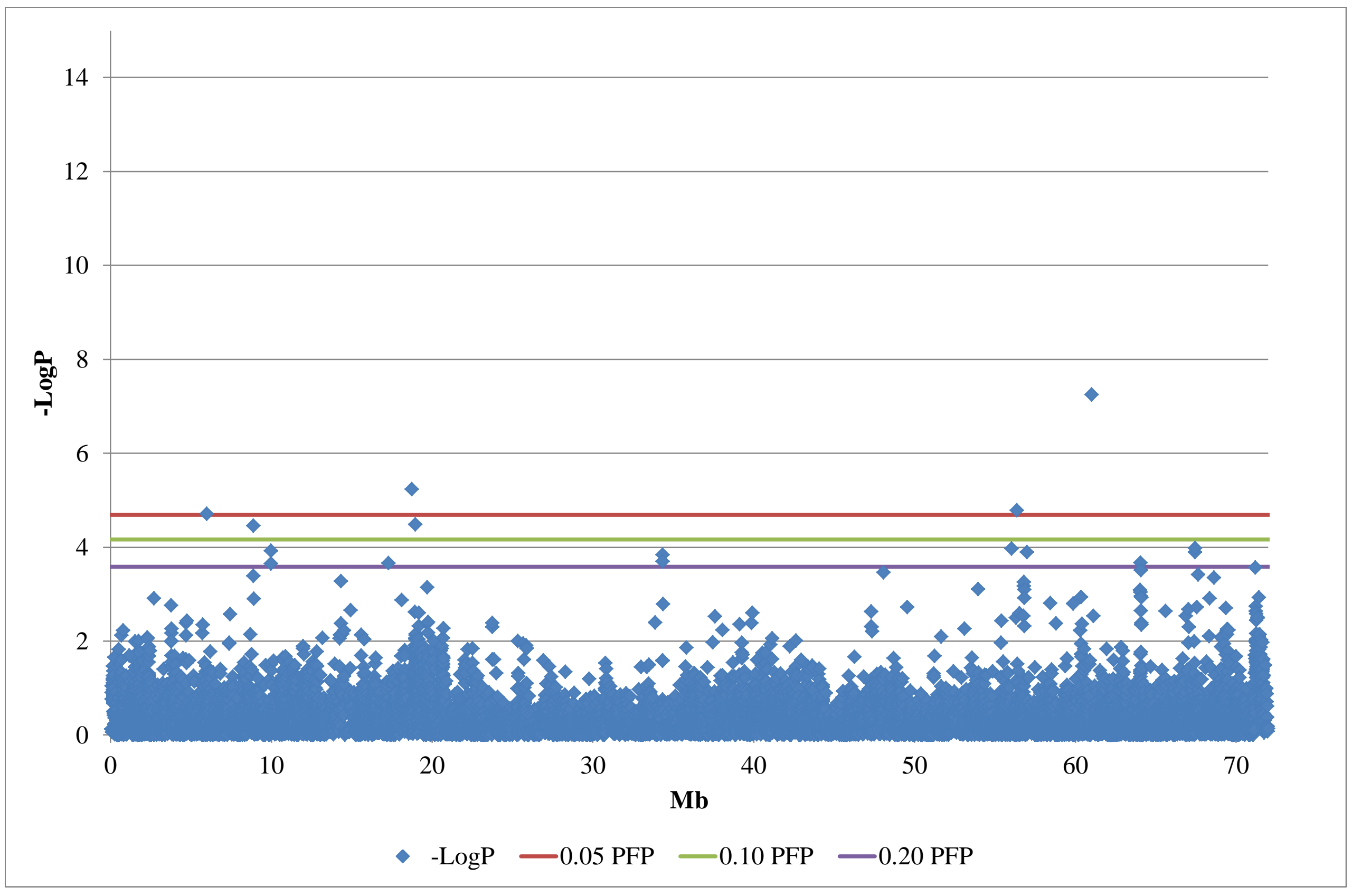

BRD pools $-\log \mathrm{P}$ chr e.xlsx 
BTA 21

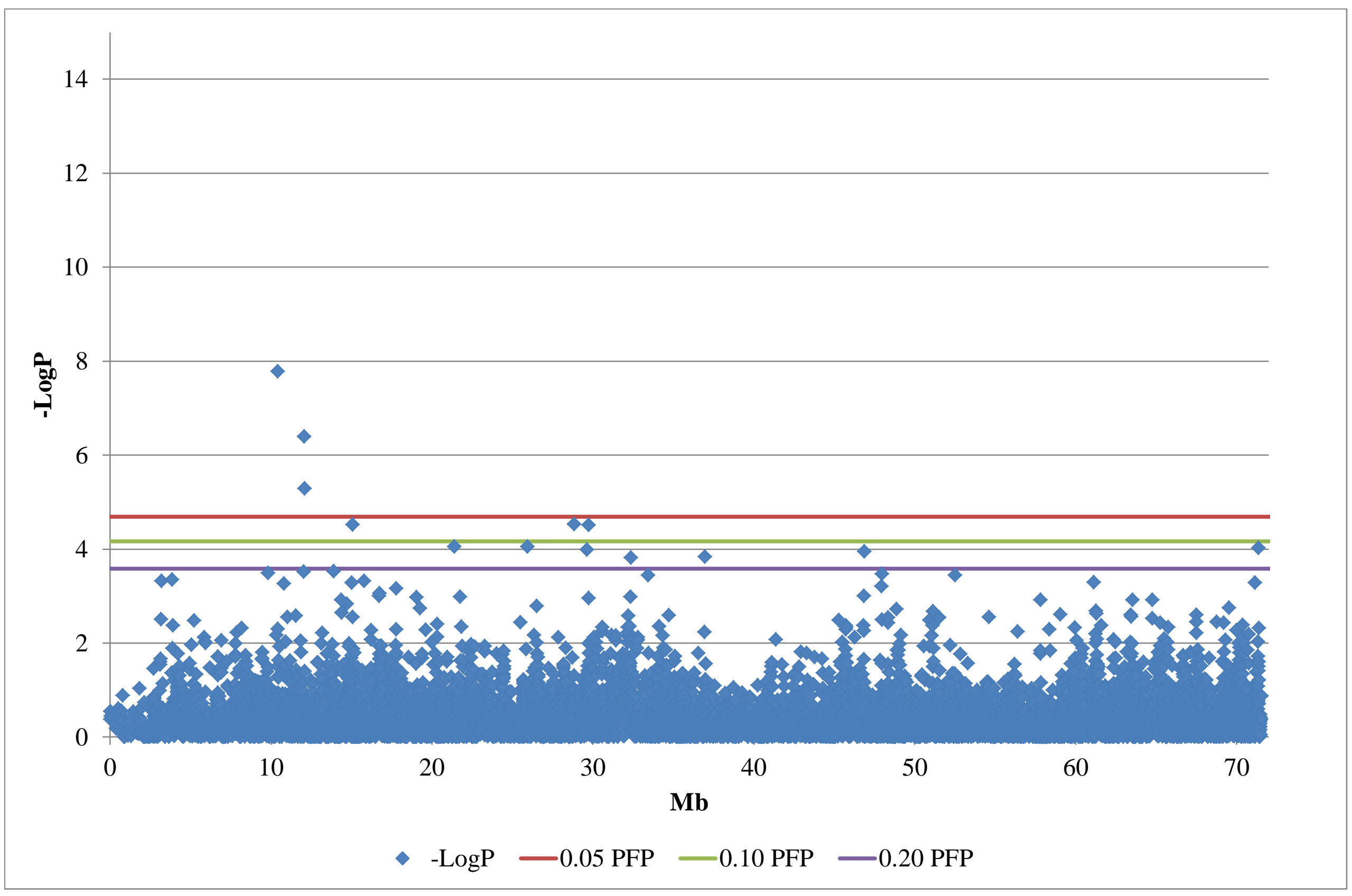

BRD pools - $\log \mathrm{P}$ chr e.xlsx 
BTA 22

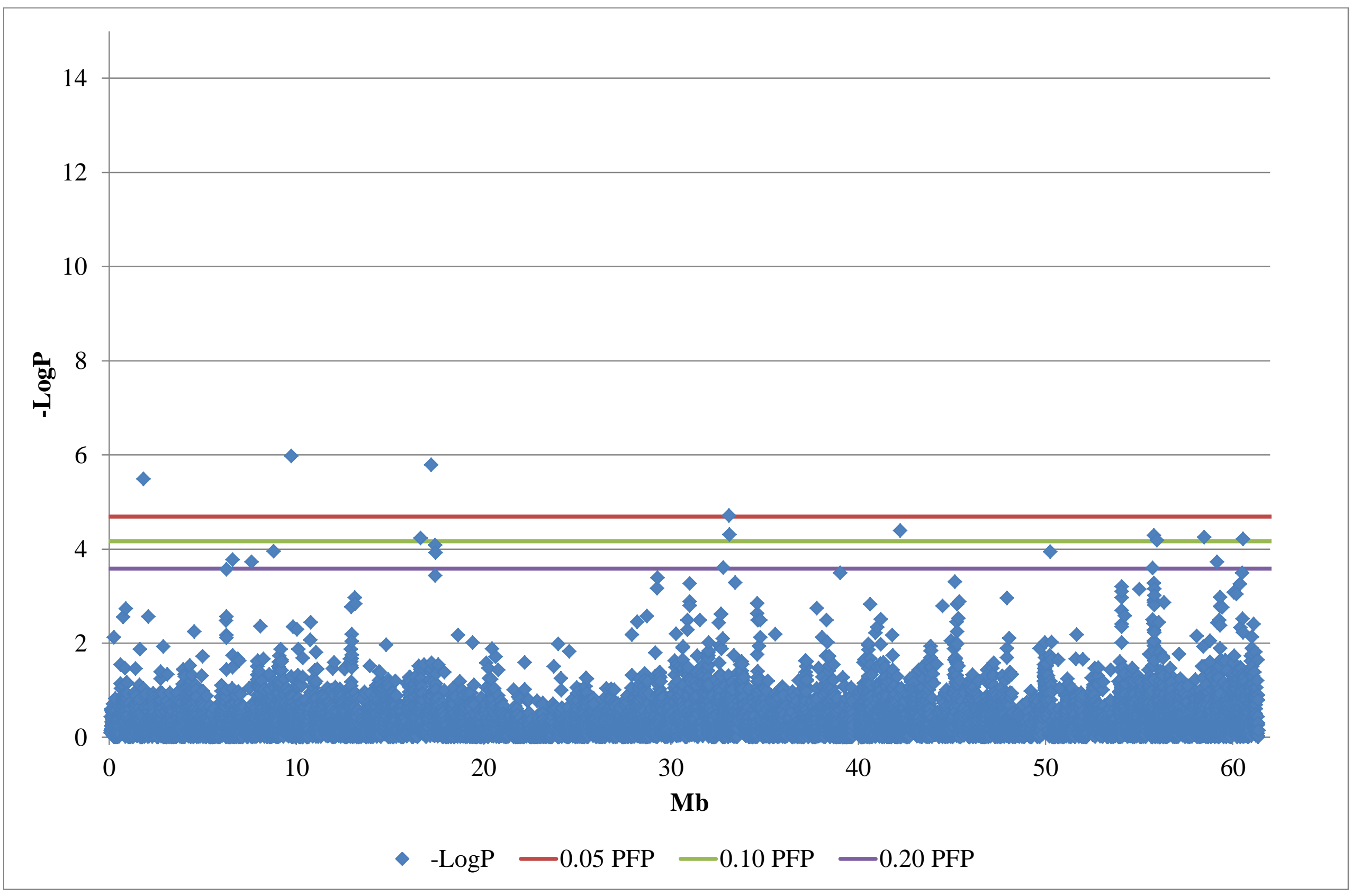

BRD pools $-\log \mathrm{P}$ chr e.xlsx 
BTA 23

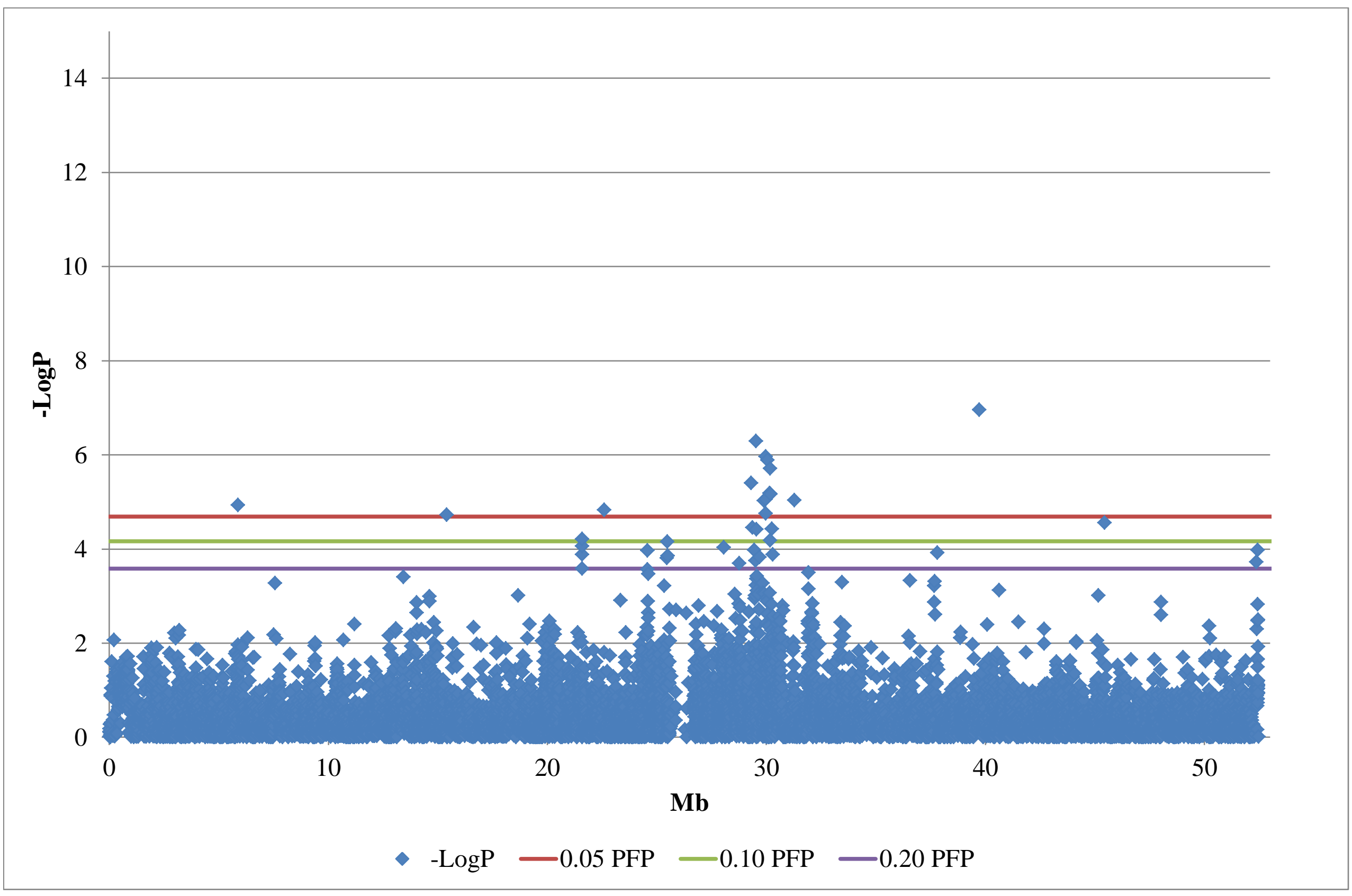

BRD pools - $\log \mathrm{P}$ chr e.xlsx 
BTA 24

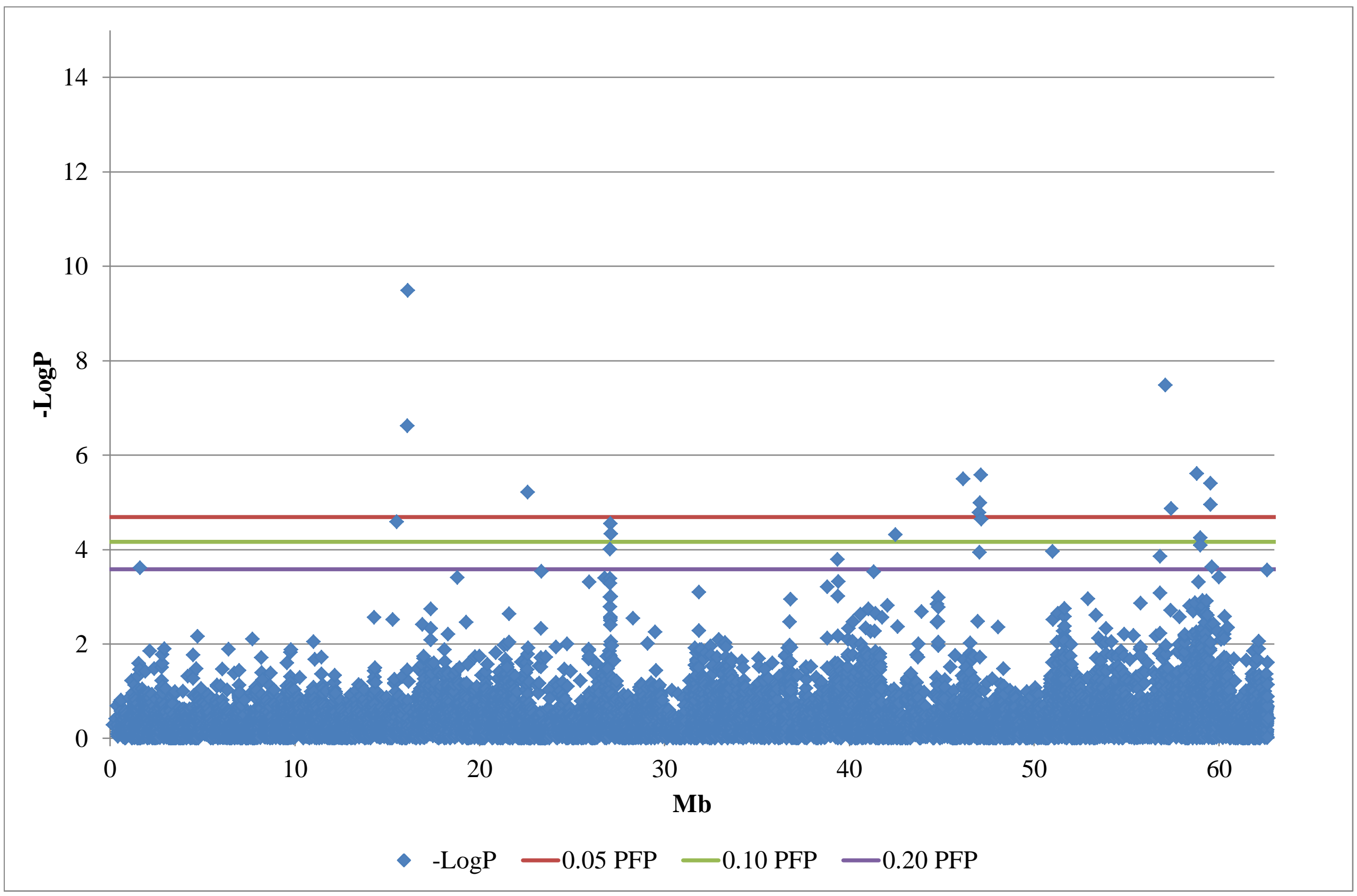

BRD pools $-\log P$ chr e.xlsx 
BTA 25

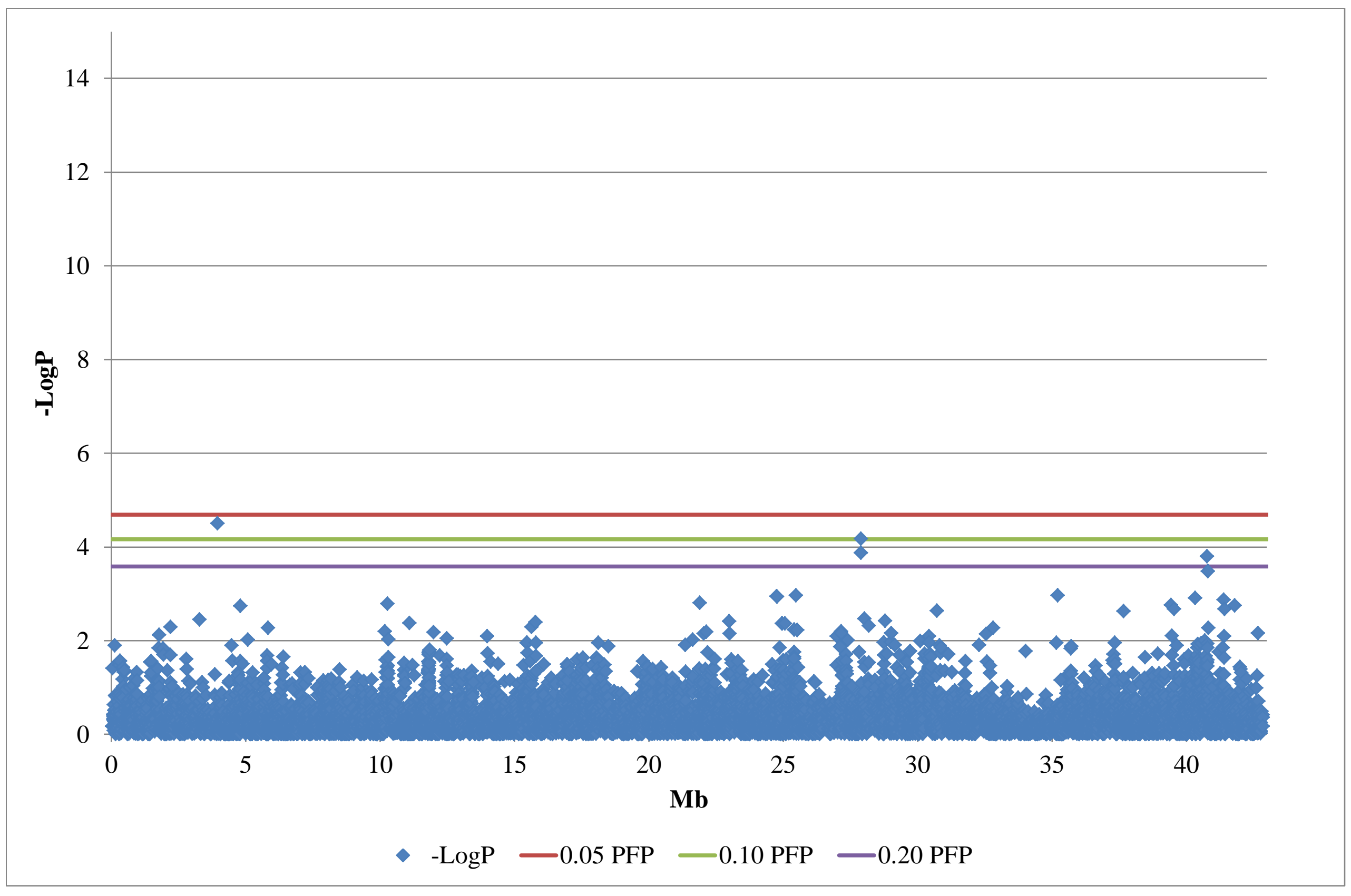

BRD pools $-\log \mathrm{P}$ chr e.xlsx 
BTA 26

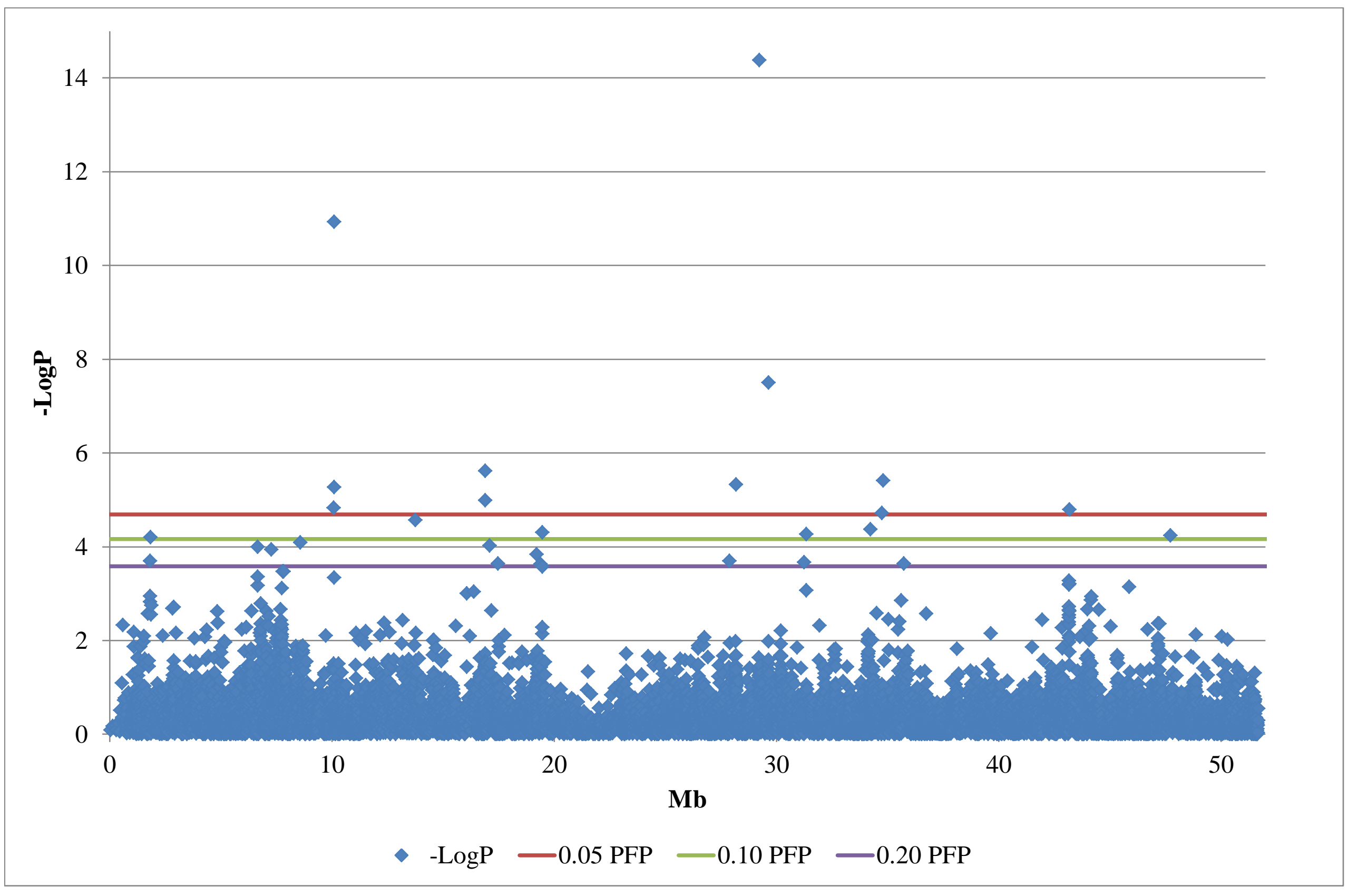

BRD pools $-\log \mathrm{P}$ chr e.xlsx 
BTA 27

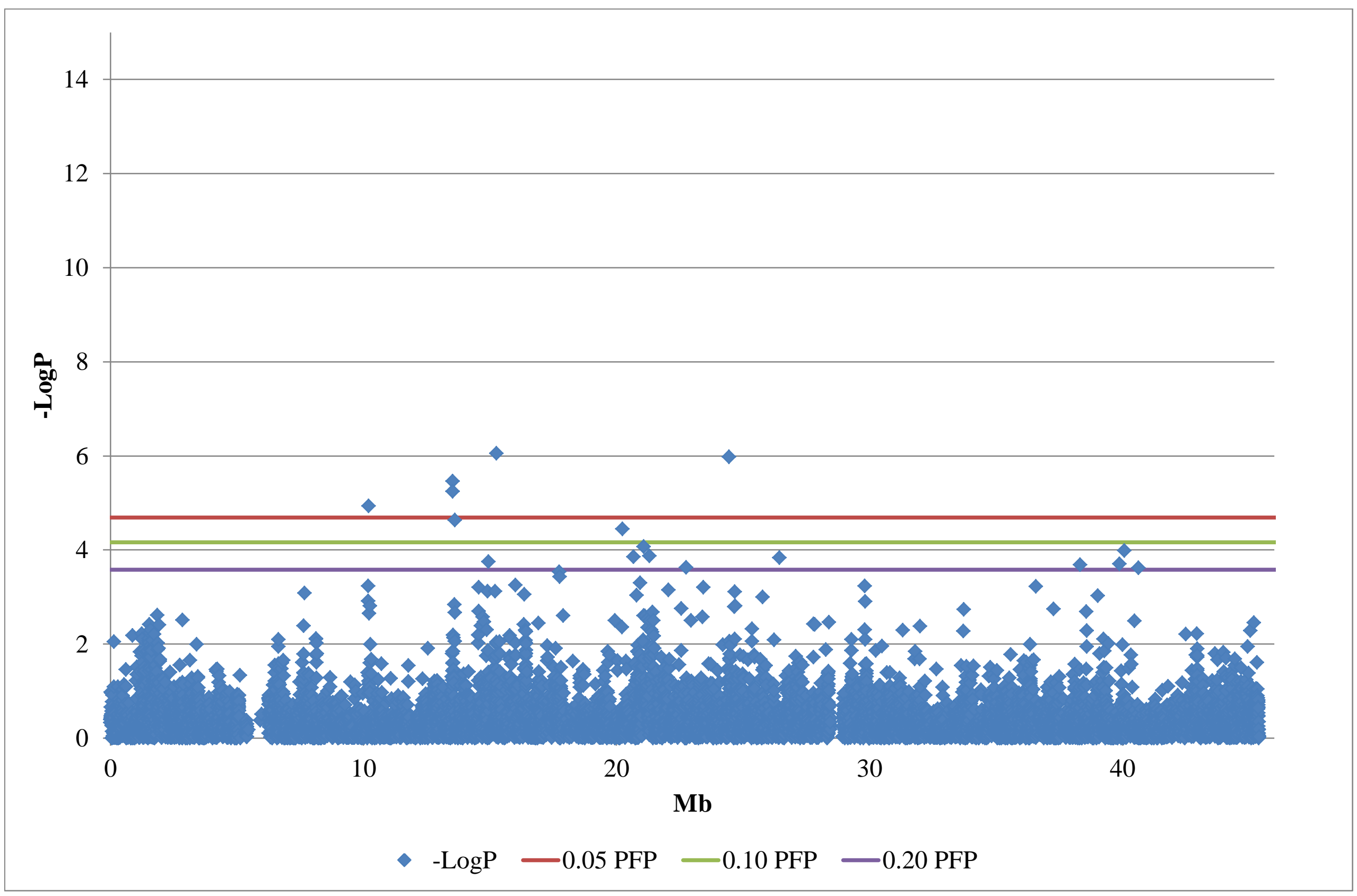

BRD pools - $\log \mathrm{P}$ chr e.xlsx 
BTA 28

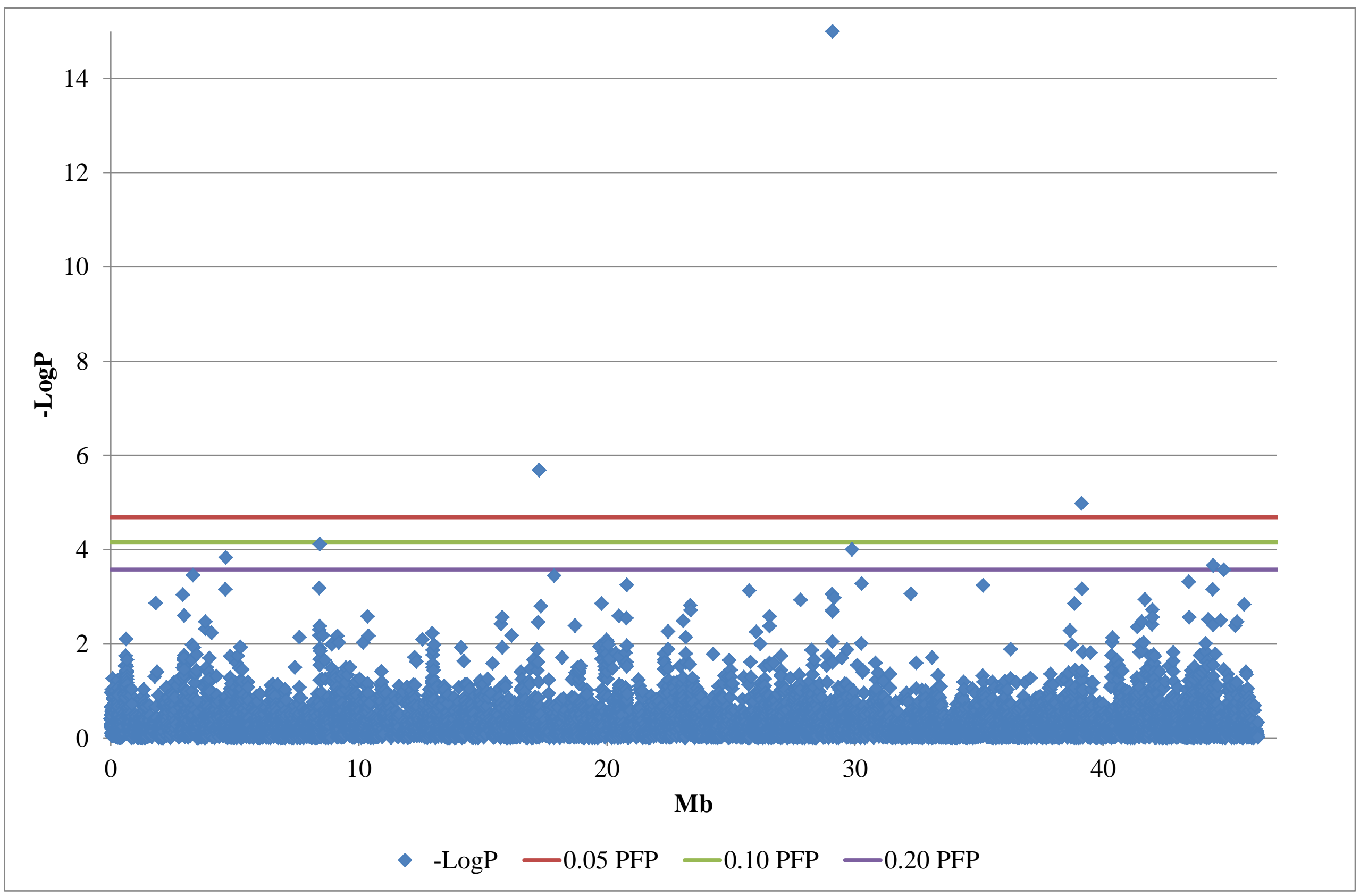

BRD pools $-\log \mathrm{P}$ chr e.xlsx 
BTA 29

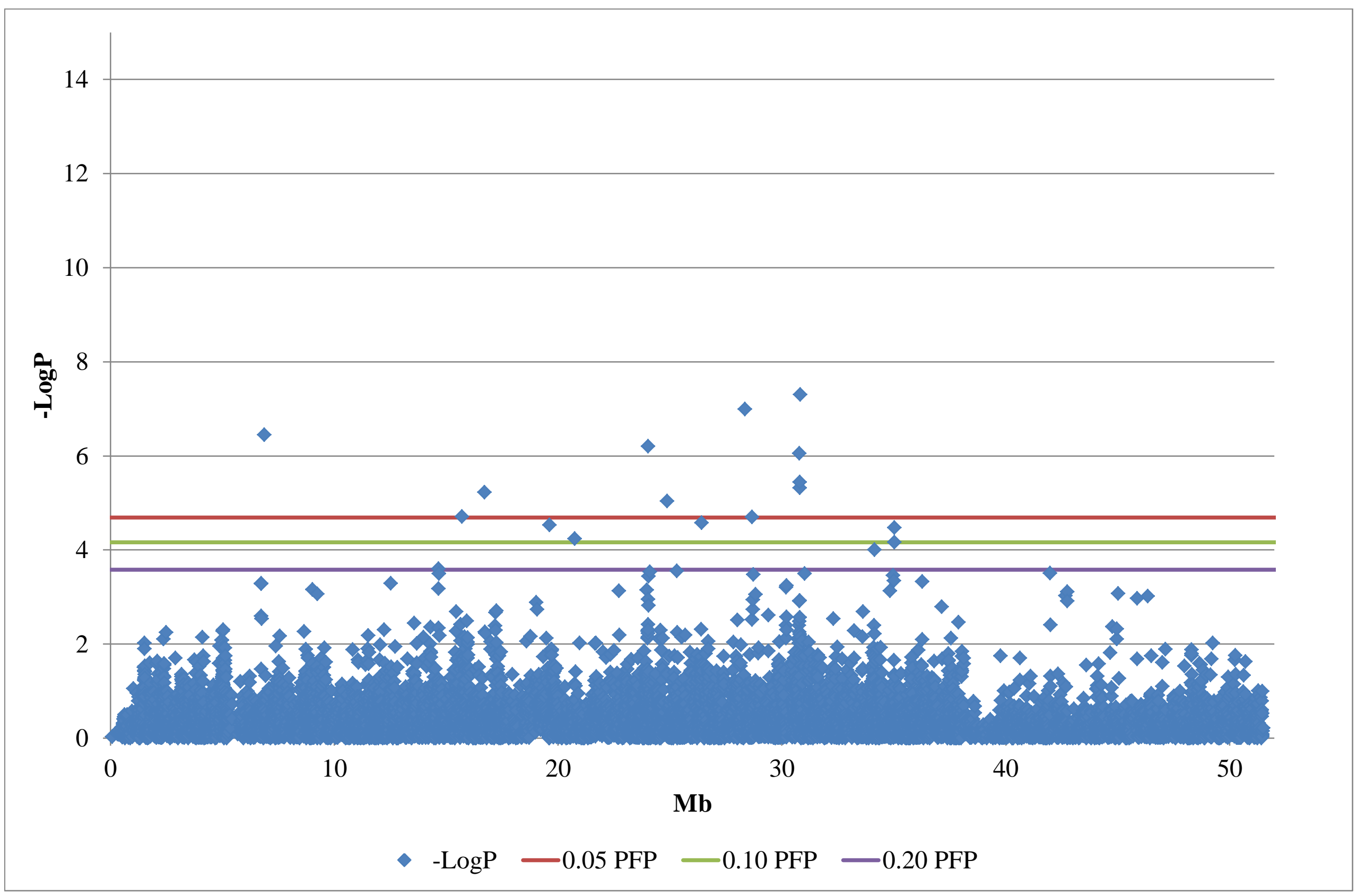

BRD pools - $\log \mathrm{P}$ chr e.xlsx 